\title{
Correction to: Radiomics score predicts acute respiratory distress syndrome based on the initial CT scan after trauma
}

\author{
Sebastian Röhrich $^{1} \cdot$ Johannes Hofmanninger ${ }^{2} \cdot$ Lukas Negrin $^{3} \cdot$ Georg Langs $^{2}$ (I) $\cdot$ Helmut Prosch $^{1}$
}

Published online: 4 May 2021

(C) The Author(s) 2021

\section{Correction to: European Radiology.}

https://doi.org/10.1007/s00330-020-07635-6

The original version of this article, published on 17 March 2021, unfortunately contained a mistake. The following correction has therefore been made in the original: The presentation of Fig. 3 was incorrect. The corrected figure is given below.

The online version of the original article can be found at https://oi.org/ 10.1007/s00330-020-07635-6

Georg Langs

georg.langs@meduniwien.ac.at

1 Department of Biomedical Imaging and Image-guided Therapy, Medical University of Vienna, Vienna, Austria

2 Computational Imaging Research Lab, Department of Biomedical Imaging and Image-Guided Therapy, Medical University of Vienna, Waehringer Guertel 18-20, A-1090 Vienna, Austria

3 Department of Orthopedics and Trauma-Surgery, Medical University of Vienna, Vienna, Austria 

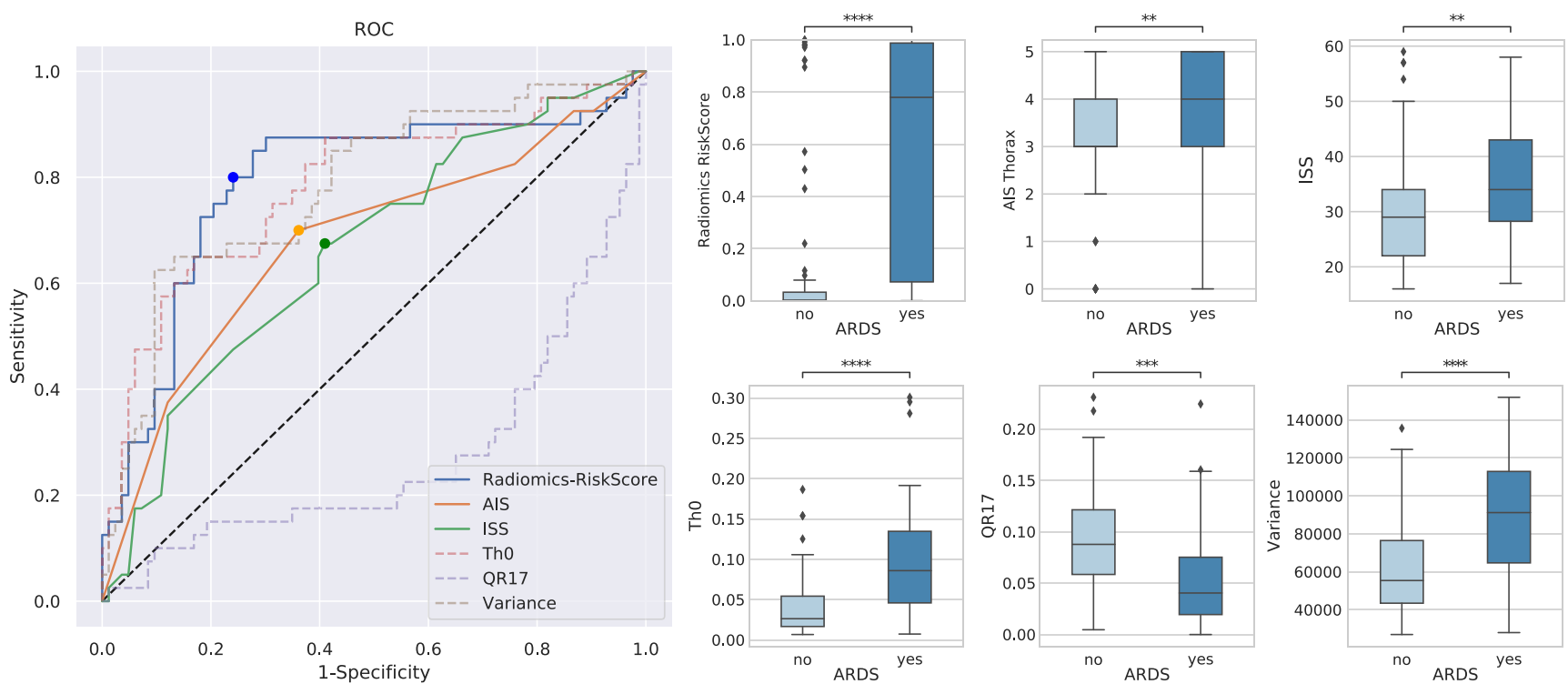

feature expressions are compared between ARDS and non-ARDS cases via boxplots and t tests. $* *: 1.00 \mathrm{e}-03<p<=1.00 \mathrm{e}-02$; $* * *: 1.00 \mathrm{e}-04<$ $p<=1.00 \mathrm{e}-03 ; * * * *: p<=1.00 \mathrm{e}-04$. ISS, injury severity score; AIS, abbreviated injury scale (for thorax)

Open Access This article is licensed under a Creative Commons Attribution 4.0 International License, which permits use, sharing, adaptation, distribution and reproduction in any medium or format, as long as you give appropriate credit to the original author(s) and the source, provide a link to the Creative Commons licence, and indicate if changes were made. The images or other third party material in this article are included in the article's Creative Commons licence, unless indicated otherwise in a credit line to the material. If material is not included in the article's Creative Commons licence and your intended use is not permitted by statutory regulation or exceeds the permitted use, you will need to obtain permission directly from the copyright holder. To view a copy of this licence, visit http://creativecommons.org/licenses/by/4.0/.

Publisher's note Springer Nature remains neutral with regard to jurisdictional claims in published maps and institutional affiliations.

$$
>
$$

